\section{SIBE2013}

The Second International Conference on Sustainable Infrastructure and Built Environment
Faculty of Civil and Environmental Engineering Institut Teknologi Bandung
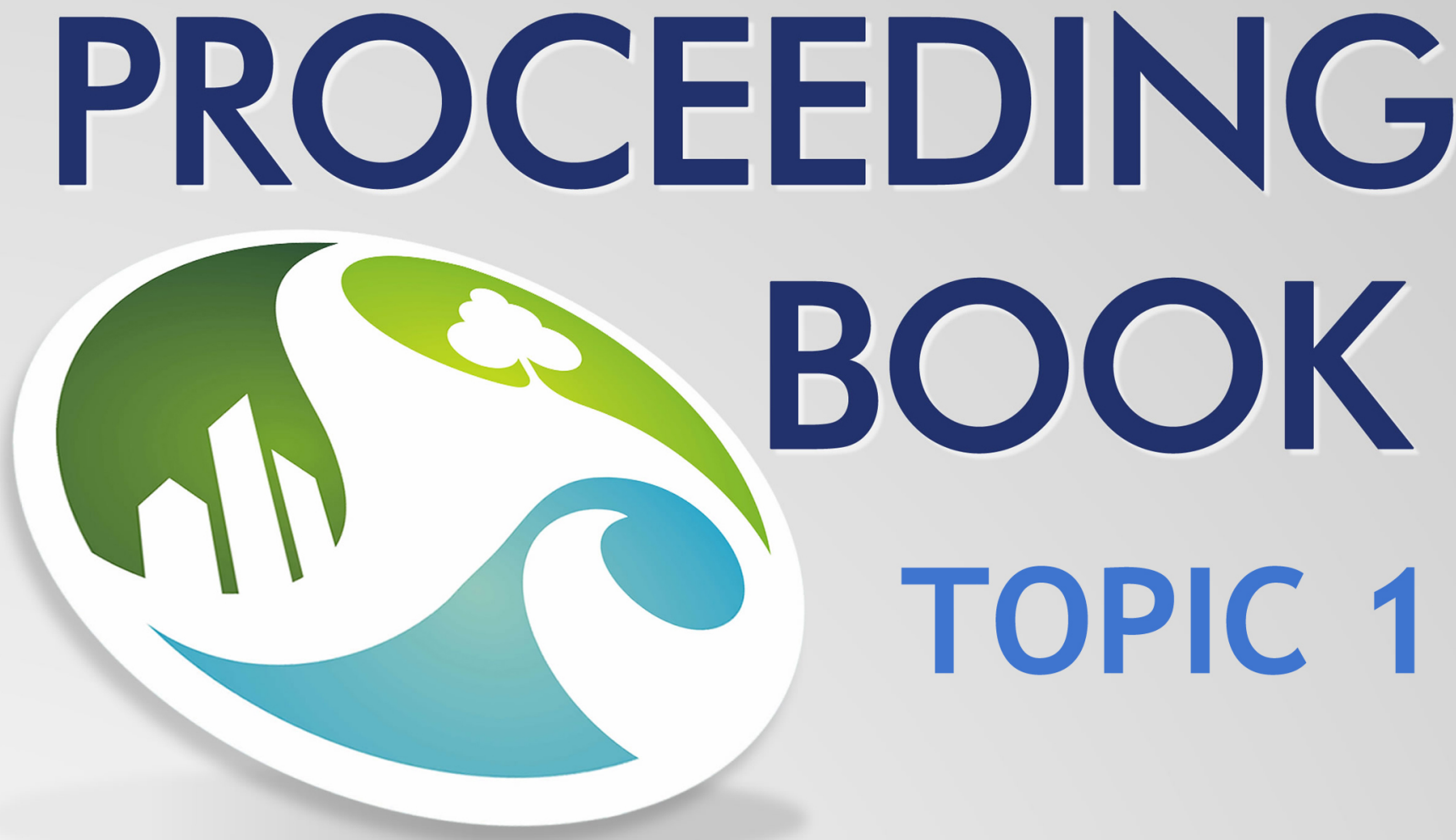

"Accelerating Sustainable Infrastructure Developement - Challenges, Opportunities, and Policy Direction"

In Collaboration with:
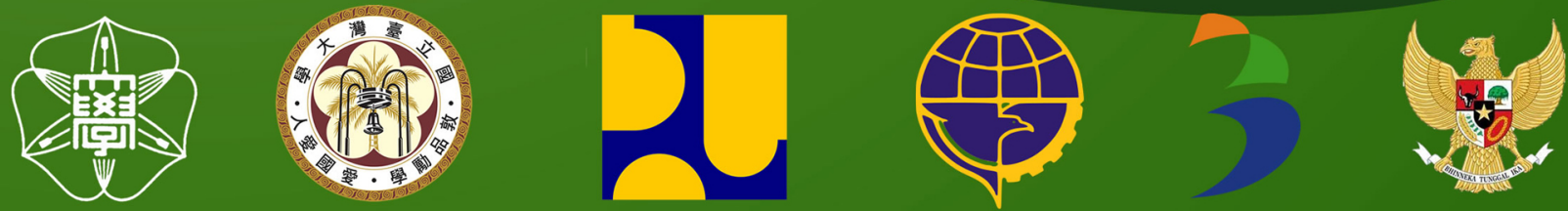

Sponsored by : 


\title{
The Chemical Characteristics of Chitosan Extracted from Green Mussels Shell (Mytilus virdis linneaus)and Its Potential Application as a Natural Coagulant
}

\author{
SINARDI ${ }^{1}$, Prayatni SOEWONDO², Suprihanto NOTODARMOJO ${ }^{3}$ \\ Faculty of Civil and Environmental Engineering, Institut Teknologi Bandung, Jalan \\ Ganesha 10, Bandung 40132, Indonesia \\ Email : 1.ina_asriadi@yahoo.com, 2prayatnisoe@yahoo.com, \\ ${ }^{3}$ suprihantonotodarmojo@yahoo.com
}

\begin{abstract}
Chitosan is a poly N-acetyl-glucosamine biopolymer, natural cationic polyelectrolyte, and biodegradable. Chitosan is obtained by alkaline deacetylation of chitin. Chitosan is extracted from green mussels shell (Mytilus virdis linneaus) and is expected to be an environmental friendly solution for abundant green shells waste.

The aim of this study is to determine chemical characteristic of chitosan about degree of deacetylation. The degree of deacetylation was calculated from IR spectrum using the Fourier Transform Infra Red spectroscopy (FTIR). The degree of deacetylation of chitosan are used to study coagulation/flocculation mechanism.

The results of the study indicated that green mussels shell was a rich source of chitosan. Chitosan was produced from No and Meyers methods through 3 subsequent processes i.e. deproteinasi, demineralization and deacetylation.The degree of deacetylation was $38.91 \%$. The Test was carried out at laboratory scale and chitosan was applied as a natural coagulant in a jar test by using synthetic water where kaolin was added to act as a suspended solid and humic acid as an organic matter in the beaker experiment. Application of chitosan as a natural coagulant was optimum at $\mathrm{pH} 9$, chitosan dose $250 \mathrm{mg} / \mathrm{L}$ and turbidity removal efficiency $92.6 \%$.
\end{abstract}

Keywords: chitosan, degree of deacetylation, flocculation, mytilus virdis linneaus, natural coagulant, turbidity. 


\section{Introduction}

Chitosan, a natural linear biopolyaminosaccharide, is obtained by deacetylation of chitin, which is the principal component of protective cuticles of crustaceans such as crabs, shrimps, lobsters, shellfish and of some fungi such as aspergillus and mucor. Chitosan applications in fields such as cosmetics, biomedical engineering, pharmaceuticals, ophthalmology, biotechnology, agriculture, textiles, oenology, food processing, nutrition, and environment. Chitosan and Moringa Oleifera have been applied as coagulant in water treatment for the removal of particulate and dissolved contaminants[1]. Chitosan is inexpensive, biodegradable and nontoxic for human[2].

Chitin can extracted from marine sources. The chitin found most in crab as $50 \%-60 \%$, shrimps $42 \%-57 \%$, squid $40 \%$, and shellfish $14 \%-35 \%$ [3]. Chitin is the most abundant natural amino polysaccharide and is estimated to be produced annually almost as much as cellulose. It has become of great interest not only as an underutilized resource, but also as a new functional material of high potential in various fields, and recent progress in chitin chemistry is quite noteworthy. Chitosan differs from chitin by the amine groups (-NH2), positively charged in acidic conditions, and it acquires interesting cationic character which is responsible for its flocculating activity[4].

Chitosan can be a potential substitute for aluminum salts and synthetic polyelectrolytes in water treatment because it can: (1) avoid the health effects from residual aluminum (III) and synthetic polymers; (2) produce biodegradable sludge; and (3) reuse the marine sources[5].

Green mussels (Mytilus viridis linnaeus) belong to the phylum molluscs and to the class bivalvia. The main constituent of the shell is calcium carbonate which are either. Waste green mussels shell are very abundant existence in Indonesia and was overall weight (meat and shells) meat content only 30\% [6]. Potential extracted as chitosan is expected to be an environmental friendly solution for abundant green shells waste.

The aim of the this study was to perform a chemical characteristics of the chitosan extracted from Mytilusvirdislinneausshells with chemical methods and characterization of the chitosan about degree of deacetylation. In addition, chitosan extracted from Mytilusvirdislinneausshells applied as a natural coagulant to remove turbidity for water treatment. 


\section{Materials and Methods}

\section{Materials}

Shell materials were obtained from the wastes of Mytilusvirdislinneausshells, were collected from a Indonesian waters, 80 mesh crushed shells as much as $100 \mathrm{gr}$.

\section{Preparation of chitosan}

Chitosan was extracted by the method of No and Mayers[7]. Deproteinization step was carried out with $3 \% \mathrm{NaOH} 1: 6(\mathrm{w} / \mathrm{v})$ at $85^{\circ} \mathrm{C}$ for $30 \mathrm{~s}$, washed with deionized water to neutral $\mathrm{pH}$ and dried at $80^{\circ} \mathrm{C}$ for $24 \mathrm{~h}$. Demineralization with $1.25 \mathrm{~N} \mathrm{HCl} 1: 10(\mathrm{w} / \mathrm{v})$ at $75^{\circ} \mathrm{C}$ for $1 \mathrm{~h}$, washed with deionized water to neutral $\mathrm{pH}$ and dried at $20^{\circ} \mathrm{C}$ for $24 \mathrm{~h}$. Deacetylation process with chitosan was prepared by alkali treatment of chitin using 45\% $\mathrm{NaOH} \mathrm{1:20} \mathrm{(w/v)} \mathrm{in} \mathrm{distiled}$ water at $140^{\circ} \mathrm{C}$ for $1 \mathrm{~h}$. The reactants were filtered, washed with deionized water to neutral $\mathrm{pH}$ and dried at $80^{\circ} \mathrm{C}$ for $24 \mathrm{~h}$.

\section{Characterization of Chitosan}

The degree of deacetylation (DD) of chitosan was determined by a from IR spectrum using the Fourier transform infrared spectroscopy. Chitosan samples prepared in the forms of potassium bromide $(\mathrm{KBr})$ disk was prepared according to the method of Sabnis and Block[8]. Approximately $1 \mathrm{mg}$ of chitosan powder and $\mathrm{KBr} 1 \%$ w/w was mixtured then pressed to form pellets. $\mathrm{KBr}$ pellets were obtained footage and put into place the infrared absorption spectra recorded the absorbance at $4000-650 \mathrm{~cm}-1$. The DD of the chitosan samples was calculated using standard method.

The hydroxyl group was the absorbance at $3450 \mathrm{~cm}-1$ and the amide group was the absorbance $1655 \mathrm{~cm}-1$. The DD of the chitosan samples was calculated using the following equation:

$$
\% D D=\left[1-\left[\frac{A_{1655}}{A_{3450}} \times \frac{1}{1,33}\right]\right] \times 100 \%
$$

Where A1655 were the absorbance at $1655 \mathrm{~cm}-1$ of the amide and A3450 were the absorbance at $3450 \mathrm{~cm}-1$ of the hydroxyl.

\section{Structure and Materials}




\section{Application of Chitosan as a Coagulant}

$$
\% D D=\left[1-\left[\frac{A_{1655}}{A_{3450}} \times \frac{1}{1,33}\right]\right] \times 100 \%
$$

Test of coagulation (Jar test) The simulation of coagulation process was carried out through a Jar test Flocculator SW1 (Stuart Scientific). Synthetic water where kaolin was added to act as a suspended solid and humic acid as an organic matter in the beaker experiment.

Chitosan solution from 1 gram of chitosan was added in $100 \mathrm{~mL}$ of $1 \%$ acetic acid (v/v) to obtain $10 \mathrm{mg}$ in $1 \mathrm{~mL}$ of chitosan (w/v).

As soon as chitosan solution was added to $500 \mathrm{~mL}$ synthetic water, the suspending solution was strongly mixed at $100 \mathrm{rpm}$ for 1 minutes. This step was followed by a slow mixing $60 \mathrm{rpm}$ for 10 minutes. Thereafter, the solution was settled for 30 minutes. Finally, to assess analytically the effectiveness of the coagulation treatment, the supernatant was removed from the top of the suspension by siphoning through measurement of the turbidity using a turbidimeterTurbiCheck (Lovibond)). $\mathrm{pH}$ was measured using a $\mathrm{pH}$ meter $\mathrm{pH}$ 300 (Hanna Instrument).

\section{Results and Discussion}

\section{The Characterization of Chitosan from Mytilus virdis linneaus shell}

Mytilus virdis linneaus shell was deproteinization by $3 \% \mathrm{NaOH}$ salution and results obtained chitin premises form coarse powder and lightly browned, then demineralized by $1.25 \mathrm{~N} \mathrm{HCl}$ solution. The main mineral content in green mussels shells was $\mathrm{CaCO}_{3}$ and $\mathrm{CO}_{2}$ gas forming when added to a solution of $\mathrm{HCl}$. Deacetylation of chitin was done by removing the acetyl group binds to the amine group using high concentrated of $\mathrm{NaOH}$ that $\mathrm{C}-\mathrm{N}$ bonds of chitin can be interrupted, thus forming the amine group $\left(-\mathrm{NH}_{2}\right)$ on chitosan.

DD indicates high purity and potential applied use of chitosan as a coagulant. Most an acetyl group on chitin was lost in the process that show the extent of (\%) deacetylation of the chitosan. 


\section{The Degree of Deacetylation and Functional Groups by FTIR}

\section{Method}

The Fourier Transform Infrared (FTIR) Spectra analyzed to characterization of chitosan isolation from green mussels shells have been done, show at fig.1.

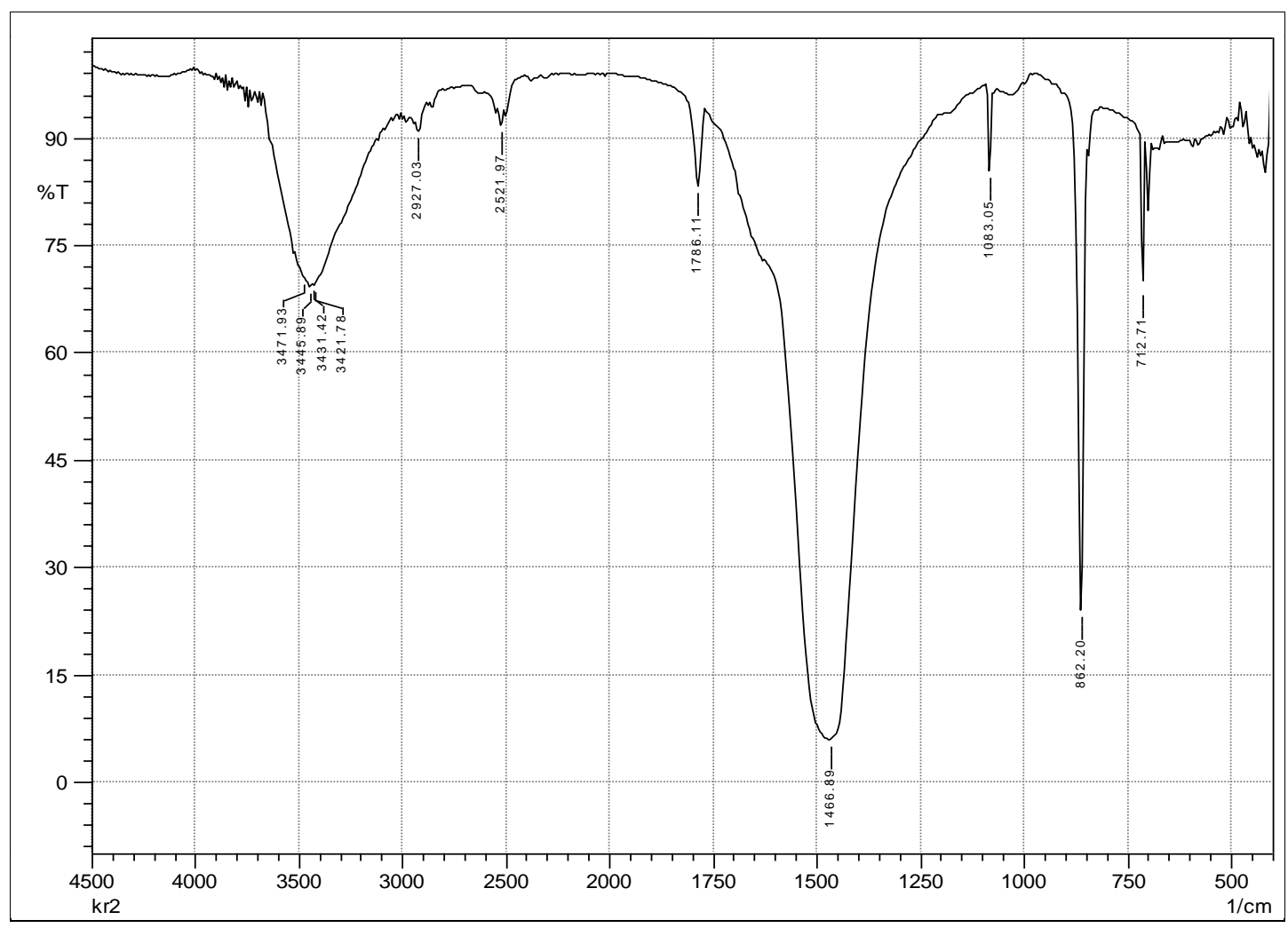

Figure 1.Determination of The Degree Deacetylation (DD) by FTIR Method.

The computation equation for DD chitosan was given below:

$$
\% D D=\left[1-\left[\frac{A_{1655}}{A_{3450}} \times \frac{1}{1,33}\right]\right] \times 100 \%
$$

$$
\begin{aligned}
& \mathrm{A}_{1655}=0,13 \\
& \mathrm{~A}_{3450}=0,16 \\
& \% D D=\left[1-\left[\frac{0,13}{0,16} \times \frac{1}{1,33}\right]\right] \times 100 \% \\
& \text { 1. Structure and Materials }
\end{aligned}
$$




$$
\% D D=38,91 \%
$$

The degree of deacetylation of chitosan was $38.91 \%$ mean that the chitosan samples containing minerals were less effective than products from which minerals had been removed. The ability to form a floc of chitosan in the coagulation-flocculation process will influenced by the degree of chitosan on deacetylation process[9].

The profiles of FTIR spectroscopy of the chitosan extracted from crab shells were almost similar, revealed the main adsorption $3200-3600 \mathrm{~cm}^{-1}$ and 2521.97 $\mathrm{cm}^{-1}$ (O-H stretching and stretching vibration ), $2927.03 \mathrm{~cm}^{-1}, 1466.89 \mathrm{~cm}^{-1}$ and $862.20 \mathrm{~cm}^{-1}$ (C-H stretching of $\mathrm{CH}_{4}$ and $\mathrm{CH}_{2}$ symmetry), $1083.05 \mathrm{~cm}^{-1}$ (C-O stretching), $3300 \mathrm{~cm}^{-1}$ and $3500 \mathrm{~cm}^{-1}$ (N-H bending of amide bonds). A new revealed adsorption with sharp intensity at $3445.89 \mathrm{~cm}^{-1}$ of chitosan spectra designed $\mathrm{N}-\mathrm{H}$ bending of amine bonds (primary amines). These spectra were characteristic and profile the main chitosan groups (NH2 primary), see fig. 1.

Hydroxyl and amine groups became very point to note because both these groups positively charged in acidic conditions, and it acquires interesting cationic character which is responsible for its flocculating activity.

\section{Application of Chitosan as a Coagulant}

Hydroxyl and amine groups in chitosan is alkaline so it can react with acids. To simplify the process of coagulation of chitosan dissolved in advance using the acid to obtain a solution of chitosan.

Chitosan interact with colloidal particles contained in the water through the process of forming a bridge between the particles and the coagulation floc so can remove turbidity of water[10], see fig 2 . 


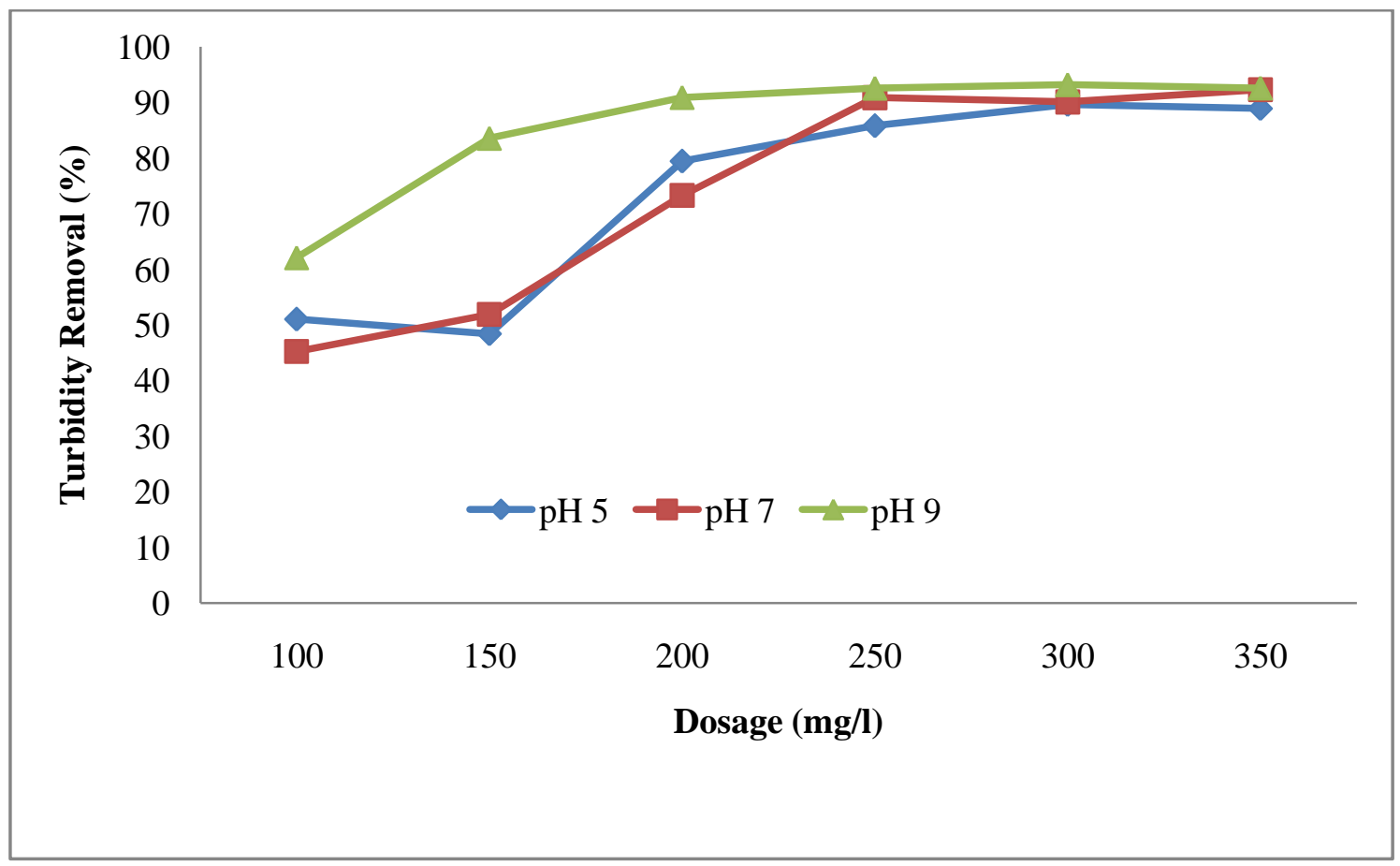

Figure 2.Turbidity Removal versus Chitosan Dosage for $\mathrm{pH}$ 5, $\mathrm{pH}$ and $\mathrm{pH} 9$

The turbidity removal ability of chitosan was increased with chitosan dosage. The similar results was obtained optimum at $\mathrm{pH} 9$, chitosan dose $250 \mathrm{mg} / \mathrm{L}$ and turbidity removal efficiency $92.6 \%$.

\section{Conclusion}

Green mussel shells can be used as raw material for making the chitosan and chitosan produced can be applied as a coagulant in the coagulation process.

\section{References}

[1] Folkard, G. K., Sutherland, J., and Shaw, R., Water Clarification Using Moringa Oleifera Seed Coagulant, On Electronic products: http://www.lboro.ac.uk/well/ resources/ technical-briefs/60, (April 3th 2013). (URL Link) 
[2] Qin,C., Li, H., Xiao, Q., Liu, Y., Zhu, J., and Du, Y., Water-Solubility of Chitosan and Its Antimicrobial Activity, Carbohydrate Polymers, 63, 367374, 2006. (Journal)

[3] Marganof, Potensi Limbah Udang Sebagai Penyerap Logam Berat (Timbal, Kadmium dan Tembaga) di Perairan, http://rudict.topcities.com/pps70271034/margonof.htm (October 10th 2011). (URL Link)

[4] Zemmouria, H, Madani D., Amna S., Hakim L., and Nabil M., Coagulation Flocculation Test of Keddara's Water Dam Using Chitosan and Sulfate Aluminium, Procedia Engineering, 33, 254-260, 2012. (Journal)

[5] Jiang, M., Xuefei Z., Yalei Z., and Jinsheng L., Flocculations of Organic Matter and Alumunium in Water Using Chitosan-Inorganic Coagulant, http://www.computer.org/portal/web/csdl/doi/10.1109/ICEET.2009.377, (October 10th 2011). (URL Link)

[6] Wardana, I., and Retno, A., Budidaya Kerang Hijau dan Permasalahannya, Jurnal Penelitian dan Pengembangan Pertanian Vol III No 2, 1983. (Journal)

[7] No, H.K dan Meyers, S. P, Preparation of Chitin and Chitosan, Dalam R.A.A. Muzzarelli dan M.G. Peter (ed), Chitin Handbook, European Chitin Soc., Grottamare, 1997. (Book)

[8] Sabnis, S. and Block, L. H., Improved Infrared Spectroscopic Method for The Analysis of Degree of N-Deacetylation of Chitosan. Polym Bull., 39, 67-71, 1997. (Journal)

[9] Kasvaei, K.H, Investigation of Deacetylation Reaction of Chitosan Behavior as Coagulant Aid, RIPI, Engineering Development of Chemical Processes, Iran, 1998. (Journal)

[10] Chung,Y.C., Hueyl L.W., Yen, M.C., and Song, L.L., Effect of Abiotic Faktors on The Antibacterial Activity of Chitosan Against Waterborne Pathogens, Bioresource Technology Journal, 88, 179 -184, 2003. (Journal)

\section{Aknowledment}

I wish to thank Prof. PrayatniSoewondo and Prof. SuprihantoNotodarmojo for useful guidance. 